\title{
ESTUDANTE E APRENDIZAGEM: RELAÇÕES MUTUALMENTE CONSTRUÍDAS
}

\author{
STUDENT AND LEARNING: MUTUALLY BUILT RELATIOSHIPS
}

RESUMO: Motivados pelo sofrimento e transformação de uma cliente ao longo do processo terapêutico, este artigo apresenta reflexões resultantes de um estudo de caso socioconstrucionista acerca dos significados atribuídos às "dificuldades de aprendizagem" para uma estudante de 15 anos. A pesquisa utilizou como caminho metodológico relatos da estudante, entrevista semiestrutu-rada e reflexões da autora/terapeuta. Percebemos que ao longo das nossas conversações os significados atribuídos ao TDAH transformaram-se, pois já não tinham peso de "dificuldades". Uma nova forma de relacionamento com o entorno educacional foi construída, uma que presa pela singularidade e responsabilidade relacional.

PALAVRAS-CHAVE: Terapia dialógica colaborativa; Pesquisa qualitativa pós-moderna; Educação.
ABSTRACT: Motivated by the suffering and transformation of a client along the therapeutic process, this paper presents resulting reflections from a social constructionist case study about the mean-ings of "learning difficulties" to a 15 years old student. The research used as methodology the students narrative, as well as a semistructured interview and reflections of the au-thor/ therapist. As results we perceive that as the conversation developed, meanings of $A D H D$ were transformed, as they no longer held the meaning of "difficulty". A new form of rela-tionship with the educational context was built, one that values singularity and relational re-sponsibility.

KEYWORDS: Dialogue collaborative therapy; Post modern qualitative research; Education.
CAROLINE

BATTISTELLO

CAVALHEIRO DE

SOUZA

BRUNO LENZI

Instituto Movimento, Florianópolis/SC, Brasil

A vivência dos autores com a educação, seja nos momentos tanto de inspiração como de repressão que vivemos enquanto estudantes, até o momento em que nos tornamos facilitadores do processo de aprendizagem para novas gerações, nos convida a desenvolver este artigo, por meio de reflexões e interesse genuíno, principalmente, com estudantes que se descrevem vivendo dificuldades em aprender, somadas a uma narrativa social de mau comportamento.

Alguns desses estudantes marcam nossas jornadas. Uma criança que chega com a queixa de "dificuldades na alfabetização" e que acreditava não ser capaz de aprender aos 6 anos de idade. Outra menina que, conhecendo a si mesma e seu desejo de atuar em uma profissão que não utilizaria conhecimentos relacionados à física, precisou adoecer para desistir do ensino médio e se voltar ao supletivo para conclusão dos estudos.

Assim como os estudantes, histórias de alguns docentes também deixaram fortes registros. Uma professora que tinha em sua turma um estudante com características de autismo, sendo que ela, sozinha, tentava lecionar e lidar com os momentos de agressividade do menino. Um professor que gerava compromisso com a biologia através de tarefas semanais de ecologia e meio ambiente para recompensar estudantes enquanto atores de mudança social. Facilitadores com vontade de fazer algo diferente pela educação, mas que muitas vezes se viam impotentes frente a algumas situações em que os processos de ensino-aprendizagem

Recebido em: 06/02/2018 Aprovado em: 11/10/2018 
não fluíam, fossem pela relação com um ou outro estudante, por limites institucionais, ou pela negligência oferecida pelo país ao desenvolvimento do contexto educacional.

Junto com esses estudantes e professores estavam famílias, coordenações pedagógicas - e tantas vezes psicólogos - e outros profissionais envolvidos na busca por tornar mais fluída a aprendizagem dessas crianças. Nessa busca, muitas vezes observamos o que Martini e Boruchovitch (2004) chamam de atribuição de causalidade, que diz respeito às interpretações individuais sobre as causas de um determinado evento. Podemos dizer que em situações de sucesso ou fracasso escolar tendemos, em alguns momentos, a responsabilizar algo por sua causa com base em nossas crenças pessoais, e essa responsabilização pode levar à exclusão de outros papéis, de outros sujeitos e processos envolvidos no contexto.

Podemos dizer que, quando falamos de saúde mental, ao atribuirmos uma causalidade única e linear para uma determinada situação corremos o risco de estarmos agindo dentro de uma visão moderna de mundo, com uma perspectiva determinista de investigação onde o diagnóstico e a solução de problemas são os focos de ação. Ao aceitarmos uma visão orgânica, complexa e relacional das situações vividas, estamos partindo de um ponto de vista do Construcionismo Social, o qual, segundo Anderson (2009), desafia um mundo cartesiano e repudia uma realidade tangível e externa que pode ser conhecida ou descrita. A maneira de abordar as situações-problema torna-se diferente, focando nos significados atribuídos à situação, isto é, a linguagem que a descreve e, portanto, propõem que a conversação pode levar à dissolução do problema. Anderson (2009), ao descrever o
Construcionismo, coloca como seu grande impacto a ideia do comportamento contextualizado:

O maior impacto desse novo paradigma ... foi o reconhecimento do conceito relacionado da contextualização do comportamento humano e do indivíduo no relacionamento com os outros. Esse conceito representa deixar de ver o comportamento humano de uma perspectiva intrapsíquica para vê-lo no contexto do sistema, com um enfoque na estrutura interativa ou interpessoal na qual o comportamento (normal ou problemático) ocorre. (Anderson, 2009, p. 23)

A complexidade da teia que permeia os desafios do processo de escolarização e os fatores que levam tantas crianças aos consultórios de psicologia encaminhadas pela escola mobilizaram as reflexões desse artigo, o qual é um dos resultados de uma monografia para o curso de Especialização em Terapia Sistêmica Pós-Moderna.

Toda pesquisa precisa lançar mão de referenciais teóricos, ou seja, formas de olhar para os seus objetos de estudos. O projeto de pesquisa em questão nasce dentro do contexto da Terapia Sistêmica Pós-Moderna, o que nos motiva a realizar esse estudo utilizando as lentes teóricas oferecidas por essa abordagem.

No que diz respeito ao traçado metodológico para esta pesquisa, optou-se por uma metodologia qualitativa na perspectiva pós-moderna. $\mathrm{McNa}$ mee (2014) aponta três mudanças significativas do olhar moderno para o pós-moderno da pesquisa qualitativa relacional. A mudança primeira diz respeito a uma passagem de uma racionalidade individual para uma racionalidade compartilhada, ou seja, 
o conhecimento e a expressão do ser no mundo é uma construção local-cultural pertencente a uma comunidade. A segunda mudança é sobre a passagem do método empírico para o da construção social, onde não temos como conhecer o mundo de forma independente de nossas formas de conversar, de nossas teorias. Por essa razão a autora afirma que as perguntas que fazemos produzem as respostas que recebemos, estamos envolvidos e somos coconstrutores da pesquisa em conjunto com os sujeitos envolvidos. Como terceira mudança, McNamee (2014) cita a linguagem não mais representacional ou como função descritiva, da visão moderna, mas sim como ação social, como constituinte do mundo. A autora reforça a ideia de que não estamos buscando verdades absolutas no campo das pesquisas pós-modernas, pois nenhuma pesquisa pode ou oferecerá o resultado definitivo, uma vez que todo conhecimento é provisório e contestável (por alguma comunidade linguística). Sendo assim, todas as explicações precisam ser vistas como locais, históricas e culturalmente específicas.

Uma vez que o objetivo central dessa pesquisa é conhecer alguns significados atribuídos às "dificuldades de aprendizagem" por uma estudante de 15 anos, optamos por coconstruir os sentidos e significados por meio de um Estudo de Caso em que a estudante estará envolvida na produção das reflexões na pesquisa. Deseja-se coconstruir um Estudo de caso que ultrapasse os caminhos da pesquisa moderna, que vá além da observação do comportamento, que seja baseado em reflexões sobre uma prática contextualizada. O estudo terá como fonte os registros dos atendimentos que a terapeuta possui com essa estudante ao longo de 1 ano e meio de atendi- mento, relatos reflexivos da estudante e entrevistas semiestruturadas com a estudante, assim como reflexões sobre a prática da terapeuta.

O processo de entrevistas Spink e Medrado (2000) nos lembra que em uma situação de entrevista é a dinâmica da relação entre pesquisador-entrevistado que abrirá caminho para esta produção. O pesquisador, através de perguntas que apontam caminhos no diálogo, proporciona a ruptura necessária à re-significação e ao desvelamento do mundo do entrevistado.

\section{O ENSINAR E 0 APRENDER - SOB A ÓTICA DO CONSTRUCIONISMO SOCIAL}

Para falarmos dos sentidos e significados atribuídos às barreiras no processo de ensinar a aprender, faz-se importante clarear a posição sobre o que é a educação sob a ótica do construcionismo social. Para tal, resgatamos uma descrição de Anderson (2011, p.37), a qual diz que:

Entendo a educação sob uma abordagem filosófica baseada em um conjunto abstrato de premissas associadas à filosofia pós-moderna que proporciona uma compreensão das pessoas como participantes singulares, ativos e engajados na construção de conhecimento, que tem relevância local e fluidez.

Podemos dizer que a educação pós-moderna se baseia na ideia de que o sujeito participa ativamente do seu processo de aprendizagem, que não se limita a ser um receptor de informações, mas sim um agente que transforma o que sabe e que constrói seu próprio conhecimento. Nesse fazer o professor é um agente de conversações, 
potencializador de diálogos transformativos. É por meio de diálogo que se aprende e se ensina; ações essas que não são mais hierarquizadas, ou seja, dilui-se a ideia de professor e estudante para formarmos comunidades de aprendizado que aprendem e ensinam por meio das interações.

A essas interações no processo de ensinar e aprender McNamee (2007) vai chamar de "ensinar como conversação" e nos diz que uma educação relacional necessita que abandonemos a ideia de que o conhecimento, ou a informação, pode ser transmitido de uma mente para outra - ao que Freire (1996) denominou de educação bancária -, mas sim que o conhecimento pode ser construído nas atividades em conjunto com outros, sendo práticas relacionais onde ambos, professor e estudante, se engajam no processo de compreensão de forma conjunta. $\mathrm{O}$ que chamamos de ensinar e aprender, Anderson (2011) denomina como processo "transformador" e "transformativo", os quais se referem ao processo criativo no qual as pessoas se envolvem umas com as outras e com elas próprias no compartilhar e questionar suas experiências.

Pensar a educação sob a ótica do construcionismo leva-nos a questionar se falar sobre "dificuldades de aprendizagem" não se torna um erro epistemológico. Quando falamos em dificuldades no aprender estamos apontando primeiramente para uma "falta", uma "dificuldade" e que está atrelada ao sujeito que aprende. César (2014) aponta que os obstáculos que nossas crianças e adolescentes enfrentam no processo de aprender e ensinar têm produzido um número crescente de crianças diagnosticadas, medicadas e encaminhadas como hiperativas, impulsivas e desatentas. Vemos os obstáculos, que acreditamos serem relacionais, trans- formados em déficits, em faltas individualizadas. Ao darmos um nome para os obstáculos enfrentados no processo escolar corremos o risco de realizar o que Gergen, Hoffman e Anderson (1996) chamaram de concretizar identidades, ação esta que limita as pessoas; cria caixas pretas, onde há pouca visibilidade para fora do problema, onde pode parecer existir poucas saídas; e formam empecilhos às definições mais pessoais e libertadoras.

César (2014) nos diz que a abordagem construcionista possibilita a dissolução da tradição individualista de construção do conhecimento, em que o indivíduo é responsabilizado/ culpado por suas dificuldades, escolhas e maneiras de viver. Sendo assim, busca-se entender o problema como algo externo, e trabalha-se no convite a estabelecer uma relação diferente com o "obstáculo", construindo novos recursos para solucioná-lo.

Em um mundo moderno cercado de especialistas que possuem a "solução certa", o "remédio mais eficaz", podemos pensar que não trabalhar com os diagnósticos e seus tratamentos pode ser uma ação até antiética, mas acreditamos que Gergen, Hoffman e Anderson (1996) fazem uma boa reflexão ao afirmarem que essa forma de ver a terapia e os diagnósticos acarreta incertezas, e entendemos que possa haver perguntas sobre a ética da incerteza, mas questionam a ética da certeza. A certeza de dizer, por exemplo, que uma criança é Hiperativa, pode esmaecer as outras coisas que ela é, e reduzir uma identidade a uma falta.

Optamos por utilizar o termo responsabilidade relacional, discutido por McNamee e Gergen (1999). Os autores exploram o conceito ao enfatizar o papel do diálogo na construção de tudo de que participamos, onde todos os sujeitos são implicados nas relações 
que estabelecem, sendo impossível isolar uma ação da outra.

"Nós mantemos ações relacionalmente responsáveis para serem aquelas que sustentem e realçam formas de intercâmbios a partir dos quais ações significativas tornam-se possíveis. Se o sentido humano é gerado através da relação, então ser responsável pelos processos relacionais é favorecer a possibilidade da própria inteligibilidade - de possuir identidades, valores e sentido." (McNamee\&Gergen, 1999, p. 18, tradução dos autores)

A ideia da responsabilidade relacional nos coloca como sujeitos ativos em todas as relações que estabelecemos; no caso da escola, professor, estudante, família, sociedade, todos fazem parte da construção de um conhecimento. Quando essa construção não consegue ser efetiva, não nos parece fazer sentido "rotular" um dos sujeitos como culpado pela obstrução dessa construção.

Pensamos então que ouvir os sentidos e significados que os diferentes sujeitos que compõem o cenário educativo produzem sobre os obstáculos no processo de ensinar e aprender parece-nos uma forma de expandir as margens dos diagnósticos, de ampliar narrativa e resgatar potencialidade.

\section{O CASO CLÍNICO PELO RELATO DA ESTUDANTE}

A descrição do caso clínico foi construída com a Flávia; nós a convidamos a falar de si e do seu processo terapêutico e ela produz um texto para ser incorporado à pesquisa e afirma que gostaria que o nome dela fosse mantido para que ela pudesse inspirar outras pessoas. Flávia inicia o processo tera- pêutico com a psicóloga Caroline em abril de 2016 e recebe o diagnóstico de Transtorno de Déficit de Atenção em setembro desse mesmo ano por um neuropediatra. $\mathrm{O}$ processo terapêutico e a pesquisa aqui apresentada caminham lado a lado. Como parceiras de diálogo, fazemos uma pausa para um olhar mais aprofundado sobre sua relação com as questões escolares, o que não resume o trabalho terapêutico, mas sim um recorte de um tema trabalhado. O relato apresentado a seguir é de autoria exclusivamente dela, sem interferências diretas da terapeuta/pesquisadora. Em seguida apresentaremos as nossas reflexões a partir do diálogo/ entrevista com base nesse relato:

Meu nome é Flávia, tenho 15 anos e fui diagnosticada com o transtorno de déficit de atenção e hiperatividade. Sempre tive muitas dificuldades na escola, então meus pais preocupados comigo e com a minha situação escolar acharam melhor eu fazer um acompanhamento com uma psicóloga.

No meu primeiro dia na psicóloga, tenho que confessar que estava com muito medo e nervosa mas com o passar do tempo vi que ela era uma pessoa incrível e que se eu continuasse ia me ajudar muito. A escola pra mim sempre foi um desafio muito grande pois sempre tive que pensar muito e manter o meu foco para as coisas que preciso fazer.

Algo ruim que acontece comigo, é que quando o professor está explicando a matéria, qualquer barulho que tiver na sala me atrapalha, por exemplo quando estão conversando ou até quando um lápis cai no chão, eu tiro totalmente o meu foco do professor e começo a prestar atenção exatamente no que eu não preciso prestar atenção. 
Mas para eu descobrir que tinha déficit de atenção, eu tive que ir a um neurologista que me receitou um remédio para melhorar minha atenção, depois disso houve melhora em mim. E fez um laudo que explicava o que eu tinha e qual era o melhor jeito dos professores me ajudarem.

Como eu tenho déficit de atenção com hiperatividade, eu sou muito agitada e tenho excesso de energia. Esse excesso de energia na minha opinião tem seus pontos positivos e negativos. Para mim ele é bom na hora que eu preciso correr, fazer algum esporte pois eu vou me cansar provavelmente muito depois de uma pessoa sem hiperatividade, mas na hora que estou fazendo uma prova por exemplo, que é o ponto ruim, tenho que ficar parada parece que é como se fosse a minha cabeça girando sem parar, então parece que tenho a obrigação de acompanhar a minha cabeça que parece que fica girando toda a hora cheia de coisas aleatórias passando, então para tentar acompanhar eu tenho que me movimentar, aí entra a hiperatividade que tinha citado anteriormente.

Outra coisa ruim para mim, é que sou muito desorganizada e presto atenção só no que eu quero. Um exemplo desse prestar atenção só no que quero na aula é assim, não gosto muito de matemática então eu não me esforço tanto para prestar atenção, mas já é diferente com o inglês que eu gosto então tento prestar o máximo de atenção que conseguir.

Como já falei, faço acompanhamento com uma psicóloga, então trabalhamos muito o déficit de atenção. Dois exemplos de coisas que fizemos é que nós assistimos a alguns vídeos para ter cada vez mais conhecimento do caso. E outra coisa, fizemos uma barreira de argila, essa barreira é algo que eu vejo na minha frente quando os meus professores estão ensinando, ela faz com que eu tire minha atenção e foco.

Mas acompanhado com essa barreira, na qual fiz de preto, fizemos uma escada para subir na grande barreira e um martelo para destruí-la. A visão de mim mesma melhorou muito depois que recebi o diagnostico pois antes eu era uma pessoa com déficit de atenção que não sabia nem que isso existia, muito menos o que era.

Por último gostaria de explicar por que gosto de conviver toda a semana com uma pessoa incrível, amiga e que sempre está lá para qualquer coisa, gostaria de explicar por que gosto tanto de ir na psicóloga Carol. Porque eu sinto como se fosse um lugar só nosso onde nós podemos compartilhar das alegrias até as tristezas.

A Carol é alguém incrivel que conheci a um pouco mais de um ano, que como ela falou desde o primeiro dia, ela veio para ser uma amiga. Fazemos várias coisas juntas como mais um exemplo, fizemos um quadro escrito "BELIVE IN YOURSELF" (acredite em si mesmo em inglês). E ele me ajudou muito pois era algo que para mim era impossível de fazer. Então com a psicóloga Carol tudo fica mais fácil e divertido de resolver. (sic) (Relato produzido em 02/09/2017)

\section{REFLEXÕES COLABORATIVAS}

Com base na entrevista dialógica realizada optamos por organizar as reflexões em três categorias de análise do conteúdo, as quais orbitam em torno da ideia dos relacionamentos, do 
eu relacional, pois tendo como ótica a perspectiva construcionista, pensamos que ao falar sobre/com o sujeito, sobre/com sua história, estamos falando das suas relações. Gergen (1997), ao discutir as identidades, afirma que elas nunca são individuais; cada uma é suspensa em um conjunto de relacionamentos precariamente situados e as reverberações sobre o que acontece aqui e agora, entre as relações, podem ser infinitas.

As três categorias de análise sobre os relacionamentos são: a pessoa e o diagnóstico; escola e a estudante; a pessoa e o terapeuta. Essas categorias, como mencionado no início do artigo, contam com os conteúdos registrados nos atendimentos terapêuticos, no relato escrito pela Flávia e na entrevista realizada.

Faz-se importante destacar que ao realizarmos um recorte, ao optarmos falar de algumas coisas e não de outras, estamos fazendo escolhas narrativas, uma escolha entre as muitas possíveis. Não temos a pretensão de aqui esgotar as reflexões sobre esses temas, nem mesmo de alcançar com objetividade um relato exato das vivências da Flávia em seus relacionamentos, como nos lembra Anderson (2009, p. 99): “é possível se aproximar da experiência de uma outra pessoa, mas nunca podemos compreender totalmente o que isso significa para ela”.

\section{0 relacionamento pessoa e diagnóstico}

- o desenvolvimento do conhecimento local

No início da sua obra Mapas da prática narrativa, Michael White (2012) relata uma conversa com Jeffrey (criança levada à terapia pelos pais com diagnostico de TDAH) e sua família. White pergunta para Jeffrey qual o tipo de TDAH que ele tem, qual a cor dele. Jeffrey não entende a pergunta e White (2012) afirma: "Ahá! Eu sabia! Agora eu sei por que o TDAH de Jeffrey está livre para sair por aí bagunçando tudo. Como ele poderia fazer o que quer que fosse para impedi-lo se ele não sabe nem a aparência do TDAH?". O diálogo de White com Jeffrey inspirou essa prática terapêutica, chamando-nos a olhar para além das descrições médicas sobre o TDAH ou qualquer outro diagnóstico. Convidaram-nos a desejar conhecer a cor do TDAH da Flávia.

Ao refletir sobre a descrição que Flávia faz do seu TDAH, lembramos as inúmeras conversas onde ela busca explicar como a "falta de memória" ou a "desatenção" ocupavam lugar na sua vida, como eram as relações dela com os sintomas. No seu relato, ela diz: "trabalhamos muito o déficit de atenção. Dois exemplos de coisas que fizemos é que nós assistimos a alguns vídeos para ter cada vez mais conhecimento do caso. E outra coisa, fizemos uma barreira de argila, essa barreira é algo que eu vejo na minha frente quando os meus professores estão ensinando, ela faz com que eu tire minha atenção e foco".

Vemos esse movimento dela de dar cor e forma ao seu TDAH como um processo que White (2012,p.36) chama de externalização do problema; ao discutir o termo, ele nos afirma que quando o problema se torna uma entidade que é separada da pessoa, e quando as pessoas não ficam atadas às verdade restritivas em relação à sua identidade e certezas negativas sobre sua vida, novas opções de ação para lidar com as dificuldades de suas vidas tornam-se disponíveis, sendo essa separação algo que propiciará que a pessoa assuma a responsabilidade de rever a sua relação com o problema. 
Ao lado da barreira Flávia fez uma escada e um martelo, uma escada para subir e um martelo para derrubá-la. É possível dizer, então, que se a barreira é o problema externalizado, o martelo e a escada são formas de rever a relação dela com a barreira, onde ela pode existir, mas não impedirá que a Flávia veja ou chegue ao outro lado. Sobre isso Flávia afirma na entrevista/ diálogo: "os degraus da escada foram a psicóloga, o remédio, meus pais, prova com consulta, a diretora me ajudou muito, os professores quando eles podem, eu acho que o que mais me ajudou mesmo foram as pessoas".

Laurentino (2017) destaca a importância de localizar o problema como circunstâncias da vida e não como definidores da sua identidade, acreditando na possibilidade de construir um modo de se relacionar com o problema, minimizando-o ou anulando seus efeitos sobre a própria vida. Com esse entendimento, perguntamos para Flávia o que é ser diagnosticada, uma vez que ela se apresenta no relato como uma menina de 15 anos com diagnóstico de déficit de atenção.

Flávia: é quando o carinha tem alguma coisa que pode melhorar, que com o diagnóstico, por exemplo o cara tem déficit de atenção, e ele não faz a mínima ideia do que é isso, ele vai e faz um exame e com esse negócio do médico ele sabe o que ele tem. É tipo um papel que mostra o que a pessoa tem. A pessoa sente o sintoma do déficit de atenção e aí esse papel comprova que ela tem isso. Antes eu não sabia o que eu tinha, agora eu consigo saber

Pesquisadora: mas tu já conhecia o teu sintoma?

Flávia: já, mas eu não sabia o que era, na verdade eu nem sabia se eu tinha alguma coisa. Acho que eu sabia, sempre soube. Antes achava que tinha esquecimento, mas agora sei que é problema de atenção, mas esse esquecimento é por causa da falta de atenção. (Trecho da entrevista com Flávia, realizada em 28 de setembro de 2017)

Percebemos na sua descrição o diagnóstico como algo externo ao sujeito, algo que uma comunidade legitimou denominar TDAH. Refletimos, então, sobre a construção social das terminologias existentes, uma vez que, como afirma Gergen (2007), as 'formas com que falamos' estão intimamente entrelaçadas com os padrões da vida cultural. Faz-se importante questionar sobre os efeitos, nas relações, dos vocabulários predominantes nos processos comunicacionais.

Quando Flávia afirma que conhecia seus sintomas, sentia as suas dificuldades de memória, atenção e que "um papel comprova o que a pessoa tem" pensamos sobre quantas vezes o conhecimento local se vê substituído por verdades que se pretendem ser transcendentais. Gergen, Hoffman e Anderson (1996) apresentam suas reflexões sobre o diagnóstico e afirmam representar a posição de um número crescente de terapeutas relacionais e pesquisadores que estão dispostos a desafiar o uso de rótulos para transtornos mentais e o impulso expansionista de medicalizar. Expõem a ideia de que implícito no DSM IV é o pressuposto de que a psicoterapia é uma relação entre um especialista que tem conhecimento e um não especialista que precisa de ajuda.

Pensando sobre a ótica do conhecimento local, o construcionismo social nos convida a realizarmos perguntas alternativas, como: Qual a intenção de um diagnóstico? Quais perguntas se 
espera que sejam respondidas em um diagnóstico? Para quem se quer comunicar o diagnóstico? Se há várias maneiras de se descrever a mesma coisa, como respeitar e trabalhar com todas as realidades? Considerar a possibilidade de múltiplos diagnósticos? Como trazer o cliente para o processo? Quais outras palavras nós podemos usar? (Gergen, Hoffman, \& Anderson, 1996).

Ao observarmos a relação que a estudante desenvolveu com seu processo de aprendizagem e sua relação com o mundo onde a dificuldade de atenção e foco se interpõe à sua frente, questionamos não o diagnóstico médico, mas sim destacamos a importância de irmos além dele. Em um levantamento rápido nas bases de dados (Scielo) podemos verificar mais de 200 artigos sobre o TDAH nos últimos 10 anos. Ter um denominador em comum, partir de uma descrição delimitada sobre um tema possibilitou que os estudos avançassem, que comunidades se debruçassem sobre formas de oferecer saúde mental às pessoas.

Exaltamos a beleza do conhecimento local não como contraposição ao conhecimento dos manuais médicos, mas sim com intenção de colocarmos em evidência processos que até pouco tempo atrás não eram aceitos como conhecimentos legítimos. Flávia fala do seu conhecimento local, vivenciado exclusivamente por ela, sobre o seu TDAH, no seguinte diálogo:

Pesquisadora: é possivel que haja uma diferença entre aquilo que a gente lê na internet da descrição de um diagnóstico, e aquilo que a pessoa descreve que é dela, que é particular dela?

Flávia: bom, minha melhor descrição foi a barreira, mas eu acredito que tem, mas tudo que eu leio na internet, todos os sintomas eu sinto. Para eu mesma me entender eu inventei a barreira, é minha e tem a minha cor (primeira era preta e a segunda roxa). A barreira foi o que me ajudou a me entender, eu fiz de preto, mas na verdade ela é transparente, fiz preto porque não gosto de preto, ela ainda aparece, mas está menor. (Trecho da entrevista com Flávia, realizada em 28 de setembro de 2017)

Dificilmente conversamos usando as palavras déficit de atenção ou TDAH; usamos a metáfora que construímos em diálogo, falamos da barreira, usamos nossa linguagem preferencial e não a linguagem médica ou outra descrição externa ao nosso encontro. Os entendimentos das metáforas eram apenas nossos, resultados das nossas conversações. Anderson (2009) nos diz que a lógica do diálogo sempre contém possibilidades de significado que surgem apenas em seu contexto, sendo essa a maravilha do diálogo.

O movimento de se apropriar do seu processo com o "problema" possibilitou com que ela vivenciasse novas formas de se comunicar com os outros e com ela mesma. Um exemplo visível é que anteriormente Flávia precisava muito que os outros a lembrassem de compromissos como provas, trabalhos. Hoje ela utiliza os recursos do seu celular como meios de se organizar a subir os degraus da escada. Ela conhece a barreira, sabe quando e como ela aparece e também como contorná-la. Ela se tornou a especialista da história dela, se apropriou do que ela precisa.

Seu conhecimento local sobre o TDAH e para além dele, do seu conhecimento sobre si mesma, possibilitou que ela significasse de forma ampla os efeitos da "falta de atenção e agitação". Em seu relato ela afirma os pontos positivos e negativos de ter muita ener- 
gia: "ele é bom na hora que eu preciso correr, fazer algum esporte pois eu vou me cansar provavelmente muito depois de uma pessoa sem hiperatividade, mas na hora que estou fazendo uma prova por exemplo, que é o ponto ruim, tenho que ficar parada parece que é como se fosse a minha cabeça girando sem parar". Flávia não reduz seu discurso aos "déficits" e sim para as características, para sua forma de conviver com sua "expressão humana" construída socialmente. Gergen (2009) nos diz que não existe expressão humana com significado por si só, e sim apenas através dos outros, de uma cultura onde seus participantes colaboram para criar seus significados.

Perguntamos à Flávia como ela se descreveria para alguém, e ela diz: "olha, eu sou uma pessoa com problema de atenção, senão fosse a atenção eu só ia tirar 10 nas provas, porque eu sou muito inteligente, muito mesmo, um grau de inteligência gigante".

Nessa fala vemos uma Flávia conhecedora de seus recursos, o que nos faz refletir se não será esse o simples objetivo de um processo terapêutico, potencializar o outro, com as suas histórias, suas ferramentas, sua rede, suas verdades locais. Contudo observamos que o relacionamento da Flávia com o seu diagnóstico possibilitou que ela buscasse conhecer com mais profundidade sintomas que ela já percebia em si mesma; conhecer as cores do seu TDAH auxiliou-a a não o deixar continuar a "sair por aí bagunçando tudo".

\section{0 relacionamento escola e estudante - a responsabilidade relacional no processo educativo}

Nesse caminho reflexivo que optamos trilhar temos como objetivos discutir as vivências que a Flávia teve com a escolarização; o diagnóstico como interlocutor entre ela e a escola, as mudanças que ela se vê fazendo enquanto estudante responsável pelo seu processo de aprendizagem e o convite ao diálogo que ela faz à escola.

Em seu relato, Flávia diz que " $a$ escola para mim sempre foi um desafio muito grande pois sempre tive que pensar muito e manter o meu foco para as coisas que preciso fazer". Durante nossas conversas no processo terapêutico lembramos de ela contar que sua vida escolar foi marcada por notas baixas, recuperações, reprovação. Percebemos que sua relação com a aprendizagem, em muitos momentos, era delicada, mas sentimos a curiosidade em entender como ela se manteve motivada e interessada, sem se queixar sobre a escola, ou ficar sem vontade de estar nessa instituição. Perguntamos na entrevista sobre este fato:

Pesquisadora: fico curiosa que mesmo tendo muita dificuldade na escola, você demonstra gostar muito dela, queria entender isso.

Flávia: sim, claro que sim. É uma coisa que eu gosto muito de ir para a escola, porque nunca gostei de ficar em casa, sempre odiei de ficar em casa. Agora até gosto mais. Sempre fui muito amiga das minhas professoras, a escola para mim é como se eu tivesse muitas amigas me ensinando e eu tendo que provar que sou capaz e sou inteligente. Se eu não fosse para lá eu não seria nada no futuro. Algumas professoras fizeram com que eu começasse a gostar mais da escola. Porque eu sou assim, se eu não gosto do professor não gosto da matéria, sempre foi assim. Eu acho professor uma coisa ótima para ser, eu acho que os professores fizeram com que eu gostasse de ir para a aula e quisesse 
aprender com eles (sic). (Trecho da entrevista com Flávia, realizada em 28 de setembro de 2017)

Vemos nesse trecho da entrevista a beleza dos processos interacionais, das relações humanas. São as pessoas que trazem para ela o sentido de estar na escola, de acreditar que é capaz. Destacamos a parte onde ela aponta a necessidade de um vínculo verdadeiro com seus professores para desenvolver bons processos de aprendizagem, o que nos conecta com a ideia construcionista social de educação. Sobre isso, Guimarães, Castelfranchi e Izique (2017) afirmam que o construcionismo social leva em conta que os estudantes trazem consigo relatos úteis do que vivem e acredita que, através do diálogo, farão uso de suas habilidades para gerar conversas de valor, ao mesmo tempo em que apreenderão a ouvir e levar em consideração o que os outros, estudantes e professores, têm a dizer.

Outro ponto ao qual voltamos a atenção é a forma como o diagnóstico funcionou como um interlocutor entre a Flávia e a sua escola, pois suas dificuldades escolares a acompanhavam há muitos anos, e a escola com o desejo de entender os motivos que levavam a essas questões solicitou que a família buscasse uma avaliação médica. $\mathrm{E}$ após o laudo a escola tomou algumas medidas diferentes, como permitir que a Flávia fizesse as provas em um local mais silencioso. Na nossa entrevista, dialogamos sobre essa questão:

Pesquisadora: estou pensando aqui no laudo e no que você falou dos professores, você sente que a escola mudou com você depois do laudo?

Flávia: mudou, mudou muito. Os professores começaram a me entender mais, a diretora que era muito rígida comigo, o que era bom também porque senão for rígida comigo eu não funciono. Às vezes eu penso que os professores não me entendem, mas eu penso que eu não sou a única da sala que eles têm muitos alunos, mas acho que eles realmente têm que, não cuidar, mas é "coisar" mais comigo, porque eu tenho um problema a mais, bem grandinho, eles têm que cuidar mais de mim (sic). (Trecho da entrevista com Flávia, realizada em 28 de setembro de 2017)

Gergen, Hoffman e Anderson (1996) questionam a ideia do diagnóstico como meio de comunicação, pois afirmam que não podemos dizer que precisamos dos rótulos para nos comunicarmos profissionalmente sobre os casos que enfrentamos, porque não há motivos para acreditar que o que você quer dizer, por exemplo, com "transtorno de oposição desafiante", é o mesmo que qualquer outra pessoa compreende com essa palavra. Para nós pesquisadores, os termos de diagnóstico nos ajudam a pensar que todos estamos trabalhando no mesmo fenômeno, mas isso pode significar criar uma falsa sensação de segurança.

Apoiados nas reflexões de Gergen, Hoffman e Anderson (1996), questionamos por que precisamos, enquanto instituições escolares, esperar um laudo médico para modificarmos nossos processos de ensino-aprendizagem com nossos estudantes, quais razões que nos impedem de não atender às individualidades e os diferentes modos de pensar. Vejo como um chamado de alerta quando, na sua entrevista, a Flávia afirma que "sem o remédio não tem jeito de ficar na sala", um alerta para a individualização dos problemas.

Guimarães, Castelfranchi e Izique (2017) dizem que o ensino tradicional, por sua base individualista, não reco- 
nhece a importância da produção relacional do significado e por isso transferir conhecimento acaba sendo o recurso mais utilizado. Dentro da leitura construcionista podemos apontar para uma compreensão relacional dos problemas visando à oportunização de diálogos transformativos.

Pensamos novamente, então, na frase onde a Flávia se vê impossibilitada de estar na sala de aula sem uma medicalização que a "auxilie na concentração" e refletimos sobre as razões que, enquanto sociedade escolarizante, fazem com que depositemos em nossos estudantes toda responsabilidade para que suas aprendizagens ocorram no tempo, espaço e modo no qual as escolas formatam suas docências. McNamee e Gergen (1999) discutem sobre as questões da responsabilização individual e dizem que, com a responsabilidade atribuída, sentimos possibilidades de correção, coerção, punição, e assim por diante, e que precisamos estar atentos às nossas práticas tradicionais de atribuição de responsabilidade, em que o único indivíduo serve como terminal crítico.

Uma diferença pode ser vista nessa mudança de foco para as "responsabilidades", como nos dizem McNamee e Gergen (1999), na ideia tradicional de que, se o outro ataca, estamos inclinados à defesa; se o outro está enganado, somos movidos a corrigir; se o outro é grosseiro, desejamos punir. No entanto, se as ações do outro não são a manifestação de um eu autônomo e unificado, mas os remanescentes de um universo de relações, então a defesa, a correção e a punição perdem o sentido, e a nossa compreensão sobre os outros nos convida a expandir o público de convidados na mesa de responsabilidades.

Recordamos das vivências que a Flávia se colocou para exercer seu pa- pel como convidada na mesa das responsabilidades e como ela convidou outros a se sentarem à mesa com ela.

Pesquisadora: como era tua relação com o estudo?

Flávia: ah eu não estudava, só mais aqui no CEST (Centro de estudos, onde atendo a Flávia e ela tem aulas de reforços escolares), agora até comecei a estudar mais, quando soube que tinha DA, comecei a fazer as provas com consulta, e assim quando não tinha resumo eu tinha que estudar direto na apostila, aí agora que comecei a fazer resumo, tenho que fazer o meu resumo e estudar ele antes de fazer a prova (a escola liberou Flávia a fazer as provas na biblioteca com resumo). $O$ diagnóstico me ajudou a saber $o$ que tenho e quando eu soube que eu tinha TDAH, eu fiquei mais preocupada e mais calma, eu descobri que o que eu tinha, tinha um nome não era uma coisa minha. (Trecho da entrevista com Flávia, realizada em 28 de setembro de 2017)

Assumir uma postura ativa na sua aprendizagem não pareceu ser sinônimo de responsabilização individual, pois ao mesmo tempo ela convidou a escola a lhe ajudar, resolveu explicar como se sentia e como esperava essa ajuda. Ela fez uma carta e entregou a todos os professores, promovendo interações que se distanciam do individualismo do TDAH para aproximar a responsabilidade relacional (Mcnamee\&Gergen, 1999) desta comunidade no desenvolvimento da aprendizagem da estudante, como ela explica no trecho:

Pesquisadora: por que é importante a carta se com o diagnostico as pessoas podem olhar na internet e saber o que o outro tem? 
Flávia: carta foi meio que "me ajuda professor", quando alguém faz uma carta ela realmente quer ajuda, o diagnóstico não "bastou para você entender o que eu tenho, talvez ajuda a você entender melhor o que eu tenho, talvez você não entende muito bem o que eu tenho", eu acredito que tenho um conhecimento maior sobre o que eu tenho do que os meus professores, mais que muita gente. Eu explicando o que tenho, pedindo ajuda, falando que eu realmente estou com dificuldade. Antes da carta eles falavam "ela tem um diagnóstico, beleza". Depois da carta eles pensaram "ela realmente está pedindo ajuda, ela está com dificuldade, temos que fazer algo" (sic). (Trecho da entrevista com Flávia, realizada em 28 de setembro de 2017)

A rede em que cada estudante/pessoa está inserido é convidada a sentar-se na mesa da responsabilidade, não como sujeitos que mereçam se culpar, mas por toda a potencialidade que as relações que ele estabelece pode produzir. Desse modo, vemos que, talvez, quanto mais ampliada for a rede, quanto mais participação e engajamento nos relacionamentos ela contiver, menos vezes iremos individualizar a culpa pelas 'dificuldades escolares".

\section{O RELACIONAMENTO PESSOA E TERAPEUTA - $O$ DIÁLOGO COMO POTENCIALIZADOR}

O tema dessa pesquisa e o relacionamento aqui apresentado carregam em si uma "presença radical", um movimento além do processo terapêutico, que nos chama para viver uma ética relacional. Esse movimento, segundo McNamee (2015), nos leva a nos perguntarmos como nossas estruturas so- ciais mais amplas e nossas formas de manter essas estruturas sociais contribuem para alienação, desengajamento, humilhação, degradação e avaliação negativa. Reconhecemos nossa própria participação na perpetuação da patologia individualizada.

Vivenciar os diálogos com a Flávia nos conectou com todas as crianças e adolescentes que caminham por estradas com "barreiras" na escolarização e ao mesmo tempo nos fizeram ter esperança na potencialização que o processo colaborativo e dialógico pode propiciar para quem o desejar trilhar. Destacamos um trecho do relato da Flávia:

Por último gostaria de explicar por que gosto de conviver toda a semana com uma pessoa incrível, amiga e que sempre está lá para qualquer coisa, gostaria de explicar porque gosto tanto de ir na psicóloga Carol. Porque eu sinto como se fosse um lugar só nosso onde nós podemos compartilhar das alegrias até as tristezas. ... Fazemos várias coisas juntas como mais um exemplo, fizemos um quadro escrito "BELIVE IN YOURSELF" (acredite em si mesmo em inglês). E ele me ajudou muito pois era algo que para mim era impossivel de fazer. (sic) (Relato da Flávia)

Chama nossa atenção a palavra "compartilhar" que ela utilizava, o que nos conecta com a essência da postura filosófica da prática colaborativa - estar com o outro de forma igualitária, acreditando na sua verdade e na sua história como algo único e especial.

Anderson (2017) apresenta sete características interconectadas das sensibilidades orientadoras de ação, as quais usaremos como base para reflexões sobre o relacionamento terapêutico entre a pesquisadora/terapeuta e a Flávia. 
Percebemos como foi desenvolvida a Investigação mútua, ao passo que estamos juntas nos processos, pensando juntas sobre as histórias que ela desejava conversar. Não eram conversas de uma especialista, que desejar resolver os problemas da Flávia, era um diálogo com Expertise relacional, onde tanto o cliente quanto o profissional trazem seus conhecimentos ao encontro: o cliente é especialista em si mesmo e seu mundo; o profissional é um especialista no espaço e no processo de relações colaborativas e conversações dialógicas. (Anderson, 2017, p.29) A especialidade que a Flávia possui sobre sua dificuldade em manter a atenção é diferente da especialidade da terapeuta sobre diagnósticos, sintomas, processos reflexivos.

Contar com conhecimento educacional e terapêutico para facilitar o nosso diálogo é diferente de partir do que sabemos previamente para tentar explicar as vivências da vida da Flávia. Para conhecê-la foi necessário manter uma postura de Não saber, buscando manter a ênfase em saber com ela, em vez de saber sobre ela, suas circunstâncias ou resultados esperados.

Era dela que vinham os temas, as questões, os dilemas, o que Anderson (2017) chama de Ser espontâneo e viver com a incerteza, pois a conversa não é guiada por mapas estruturados que definem como a conversa deveria parecer ou se desdobrar. Sobre essas conversas, Flávia diz na entrevista:

Pesquisadora: no final da carta tu fala assim: eu sinto como se fosse um lugar só nosso, onde nós podemos compartilhar das alegrias e das tristezas, podes me explicar essa frase?

Flávia: é tipo uma amiguinha, que sempre está lá, se a tia está com qualquer problema, coisa de escola amiga, qualquer coisa. Carol é tipo diferentona, um lugar especial. Com uma amiga eu falo quase tudo, mas aqui eu dou os mínimos detalhes (sic).

Esse trecho nos fez refletir sobre o fato dessas conversas serem Orientadas para a vida cotidiana, ou seja, eram semelhantes à maneira como nós interagimos e conversamos no cotidiano da vida. Estar com a Flávia e dividir tantos momentos ao longo de 1 ano e meio de conversas exigiu da terapeuta Ser pública quanto aos seus pensamentos, tornando alegrias e receios visíveis para ela. Por exemplo, quando ela iniciou o remédio para o déficit de atenção e foi conversado sobre as inquietações sobre o tema, ou sobre algumas interações com a escola que não haviam deixado a terapeuta tranquila.

Por fim, é possível dizer que a relação pessoa e terapeuta vivenciada foi permeada por Transformações mútu$\underline{a s}$, onde a terapeuta estava ativamente envolvida em um complexo processo interativo de resposta contínua com a Flávia, bem como sua própria experiência e conversações internas.

\section{CONSIDERAÇÕES FINAIS}

Essa jornada de reflexões, construções, foi pensada colaborativamente, afinal, optamos por apresentar sentidos e significados de outra pessoa que, de forma tão generosa, aceitou nosso convite para olharmos de forma mais profunda um processo terapêutico. Colocamo-nos como sujeitos inteiros nesse processo de pesquisa; ao falarmos da Flávia e suas vivências frente ao TDAH, falamos de nós, terapeutas, professores, estudantes, pesquisadores curiosos, como nos lembram Shagoury e Miller (2000). 
Essencialmente, a pesquisa não é mais do que um estado mental... uma postura amável e receptiva às mudanças ... A pesquisa é um esforço por tornar melhores as coisas e fazer com que o momento da mudança não nos pegue adormecidos. $O$ pesquisador tem uma mente que resolve problemas, em contraste com a mente conformista. É a mente do amanhã, em vez da mente de ontem. (p.18)

Ao início da pesquisa tínhamos como objetivo "conhecer colaborativamente alguns sentidos e significados atribuídos às "dificuldades de aprendizagem" por uma estudante de 15 anos". Refletindo sobre o alcance do mesmo, percebemos que nos aproximamos desse conhecimento, dos sentidos e significados, mas cada vez que nós os conhecíamos eles também se modificavam, eles já não eram mais os mesmos. Percebemos que ao longo das nossas conversações os significados atribuídos ao TDAH modificaram-se, e até mesmo dissolveram-se, pois já não tinham peso de "dificuldades"; passaram a ser formas de ser e estar no mundo - de expressar a singularidade de nossa participante.

Este relacionamento transforma nosso entendimento de educação e nos prepara para encontrar com nossos estudantes como estudantes do novo, não alunos (sem luz) submetidos à autoridade do mestre. Nós aprendemos com, ao explorar os conceitos que apresentamos, ao nos esforçarmos para alcançar o entendimento mútuo. Afastamo-nos de práticas que problematizam as formas singulares de aprendizagem, para reconhecer e legitimar tais linguagens, aproveitando-as como potenciais dos estudantes, não deficiências. A nova prática educacional dialógica constrói com todos os participantes o roteiro da aprendizagem, as formas facilitadoras de estudo e maneiras criativas de avaliação dos conhecimentos produzidos.

Nós enfatizamos: (a) ampliar participação e encontrar formas de não marginalizar vozes participantes; (b) reduzir o controle sobre a direção da conversa, para que os interesses locais sejam priorizados; (c) recompensar estudantes com respeito e interesse, em oposição a correções; (d) substituir o objetivo da Verdade para as possibilidades de múltiplas realidades. Convidamos facilitadores a abrir mão de seus roteiros e ppts para arriscar seus status de mestres do conhecimento em direção à confiança neles mesmos e nos processos coletivos, invocando apenas conteúdos relevantes à comunidade. Dedicamo-nos a aproximar o contexto de estudo do mundo através de ações ecológicas que compartilhem o conhecimento construído com outras pessoas e contextos.

$\mathrm{Na}$ semana que antecedeu a escrita das reflexões finais, Flávia entregou um certificado, de que ela é aluna destaque do $9^{\circ}$ ano, tendo ficado em $9^{\circ}$ lugar na escola na avaliação acadêmica sistemática, com mais 62 estudantes. De estudante com "muitas dificuldades" na escola ela passa a ser aluna destaque. Sentimos uma alegria imensa em estarmos partilhando dessas conquistas ao lado dela, e por vermos solidificada a ideia de que não somos definidos por nossas dificuldades, ou nossas barreiras, somos um constante movimento da vida, onde as possibilidades são indefinidas. 


\section{REFERÊNCIAS}

Anderson, H. (2009). Conversação, Linguagem e Possibilidades: um enfoque pós-moderno da terapia. São Paulo: Roca.

Anderson, H. (2011). Uma perspectiva colaborativa sobre ensino e aprendizado: a criação de comunidades de aprendizado criativo. Nova Perspectiva Sistêmica, 20(41), 35-53.

Anderson, H.(2017). A postura filosófica: o coração e a alma da prática colaborativa. In M. Grandesso (Org.), InPráticas colaborativas e dialógicas em distintos contextos e populações: um diálogo entre teoria e prática (pp. 21-34). Curitiba: CRV.

César, A. B. C. (2014). TDAH: o problema e seu nome para além das categorias diagnósticas. Nova Perspectiva Sistêmica, 49 (23), 34-47.

Freire, P. (1996). Pedagogia do Oprimido. São Paulo: Paz e Terra.

Gergen, K. J. (1997). Realities and relationships. Cambridge: Harvard University Press.

Gergen, K. J. (2009). Construção social e comunicação terapêutica. Nova Perspectiva Sistêmica, 18(33), 9-36.

Gergen, K. J, Hoffman, L., \& Anderson, H. (1996). Is Diagnosis a Disaster? A Constructionist Trialogue. In: F. W. Kaslow(Ed.), Handbook of relational diagnosis and dysfunctional family patterns (pp. 102-118). New York, US: John Wiley \& Sons.

Guimarães, L. A., Castelfranchï, M., \& Izique, P. (2017). A sala de aula: um encontro entre seres humanos. In Práticas colaborativas e dialógicas em distintos contextos e populações: um diálogo entre teoria e prática (pp. 631-654). Curitiba: CRV.
Laurentino, J. (2017). Considerações sobre a prática pós-moderna no trabalho em torno da desconstrução da identidade construída a partir do diagnóstico de transtorno mental. In Práticas colaborativas e dialógicas em distintos contextos e populações: um diálogo entre teoria e prática (pp. 247270). Curitiba: CRV.

Martini, M. L \&Boruchovitch, E. (2004). A teoria da atribuição de causalidade: contribuições para a formação e atuação de educadores. Campinas, SP: Alínea.

Mcnamee, S. (2014). Construindo conhecimento/ construindo investigação: coordenando mundos de pesquisa. In C. Guanaes-Lorenzi \& M. Mocheta (Orgs.), Construcionismo social: discurso, prática e produção do conhecimento (pp. 105-132). Rio de Janeiro: Instituto NOOS.

Mcnamee, S. (2015). Radical presence: Alternatives to the therapeutic state, European Journal of Psychotherapy \& Counselling, 17(4), 373-383.

Mcnamee, S. (2007). Relational Practices in Education: Teaching as Conversation. In Anderson, H. e Gehart, D. (Org.), Collaborative Therapy: relationships and conversations that make a difference (pp. 313-336). London: Routledge.

Mcnamee, S. \&Gergen, K. (1999). Relational Responsibility: Resources For Sustainable Dialogue. Thousand Oaks: Sage.

Shagoury, R. \& Miller, B. (2000). El arte de la indagación en el aula: manual para docentes investigadores. Barcelona: Gedisa

Spink, M. J. P. \&Medrado, B. (2000). Produção de sentidos no cotidiano: uma abordagem teórico-metodológica para análise das práticas 
discursivas. In M. J. P. Spink(Org.), Práticas discursivas e produção de sentidos no cotidiano: aproximações teóricas e metodológicas (pp. 26-37). São Paulo: Cortez.

White, M. (2012). Mapas da prática narrativa. Trad. Adriano Migliavaca. Porto Alegre: Pacartes.

\section{CAROLINE BATTISTELLO CAVALHEIRO \\ DE SOUZA}

É psicóloga, pedagoga, mestre em Educação. Instituto Movimento, Florianópolis/SC.

E-mail: carolinebattistello@gmail.com

\section{BRUNO LENZI}

É psicólogo e terapeuta dialógico. Instituto Movimento, Florianópolis/SC.

E-mail: brunoplenzi@gmail.com 